\title{
PROVIDING HOUSEHOLD CUSTOMERS WITH SMART METERING DATA ON MOBILE DEVICES
}

\author{
Syuzanna Hakobyan, Jan-Philipp Kohlbrecher, Johannes Pickert, Uwe Grossmann \\ University of Applied Sciences and Arts Dortmund, Emil-Figge-Str. 44, 44227 Dortmund, \\ http://www.mbms.fh-dortmund.de \\ syuzanna.hakobyan@fh-dortmund.de, jan-philipp.kohlbrecher@fh-dortmund.de, \\ johannes.pickert@fh-dortmund.de, uwe.grossmann@fh-dortmund.de
}

\begin{abstract}
One option for reducing carbon dioxide emissions is the future use of renewable instead of fossil resources. A consistent prerequisite is the optimization of household customers' energy consumption behavior. The suitable visualization of energy data, corresponding costs and tariff information on mobile devices is essential to achieve this goal. Energy data are acquired by a smart meter and transferred over wireless networks to a mobile device to provide the customer with relevant information about his current energy usage. The household customer is hence enabled to manage his energy consumption, to hold the optimal load and meet the optimum price. Suitable typs of visualization, specific for different tariffs, are identified and presented together with necessary technologies and methods for communication and data access and delivery.
\end{abstract}

Keywords: smart metering, energy usage, wireless communication, user interfaces, web services, mobile devices.

\section{INTRODUCTION}

The reduction of carbon dioxide emission is one of the primary tasks of EU and national policies. To achieve this, energy production has to be changed to use renewable instead of fossil resources. Moreover, the household customer is required to change his attitude using energy by reducing his total annual energy usage and by managing the energy demand to avoid load/demand peaks. Demand peaks cause problems in electricity production and energy distribution within grids. Energy generation plants always need to meet the exact capacity demanded. Generally, the objective is to reach the best conformity of the household's energy consumption profile to the energy provider's supply profile and resp. the energy cost profile. Smart metering technologies enable electricity providers to effectively reflect the change in energy usage. The idea is to use demand response to influence load curve patterns [2], i.e. the change of demand as reaction to price changes [3]. This means introducing new pricing models and new tariffs. Essential for motivating the household customer to change his behaviour of using energy is to provide him with specific information about his current energy load, his usage and the corresponding costs, i.e. tariff information.
The primary target of the work presented in this paper is visualizing smart meter information and therefore giving household customers an opportunity for analyzing their energy usage. Different approaches are discussed for providing necessary and specific information conveniently on mobile devices, e.g. smart phones. Three tariffs, a time variable, a load variable and a tariff depending on total usage together with specific data visualizations and modes of data access are presented. Moreover, the mobile and wireless communication path from the smart meter or from the energy provider's enterprise resource and planning system to the mobile device (smart phone) is discussed. Preliminary results have been presented previously by Kohlbrecher et al. [16].

\section{RELATED WORK}

Visualizing detailed information on small screens of mobile devices is an important topic. Since mobile devices are used in changing contexts, there is a difference to the same situation with a desktop PC. Nielsen [22] found four main usability hurdles for mobiles devices: small screens, awkward input, download delays and miss-designed sites. Guidelines for designing apps are given by Keck [13] and for designing mobile web sites by the $\mathrm{W} 3 \mathrm{C}$ consortium [27]. The guidelines describe how to design an app or 
a website which can be used and understood easily by the user. An app or website has to be designed along the paradigms of the operating system, for example the back button in iOS is located in the upper left corner as a standard. The corresponding app or website has to follow accordingly.

Leung et al. [18] found age-related differences with the reception of mobile device icons. The W3C consortium [27] offers a mobile OK Checker for validating and optimizing mobile websites.

The decision of using either an app or a website approach depends on the field of application. It is an individual decision and there is no general solution. Advantages and disadvantages are shown by Gather [11].

A software system for visualizing smart meter data on personal computers is developed by Dr. Neuhaus [4]. A similar app for iPhone and iPad was presented by enexoma AG [6].

Kunold et al. [14] developed a smart metering controller (SEC) for wireless transmission and storage of smart metering data within the customer's household. Data analysis and visualization is performed on a notebook.

\section{DATA PRIVACY AND SECURITY}

Besides the technical solutions of transfering, storing and visualizing energy data data privacy and security is a frequently discussed issue.

Depending on the selected tariff, energy load data items have to be recorded and stored. Data of high granularity, i.e. high resolution in time, storing one load/consumption item per minute for example will be generated. Such precise energy consumption profiles will be generated showing sensitive information concerning the lifestyle of the person or family living in the corresponding household. Thus, data privacy and security will become an important issue. Consequently, as a guideline profiles of high granularity of one household should not leave this household. The energy provider needs profiles of such granularity for forecasting purposes, but these profiles may be of high aggregation, i.e. profiles aggregated over several households of a region. In this context a very important objective is the rational organization of data, which is safe to data misuse [25].

Due to the unbundling of the energy market by the EU the number of the participants in the energy market has risen, for example the German energy law (EnWG 2008) introduces the option of authorizing an independent measuring point operator and/or service provider. There is an increasing number of interfaces between market participants exchanging detailed energy consumption data for billing or forecasting purposes.
Basically four groups of data can be distinguished: consumption profiles, user's data, device data and data which deliver information about the billing system. Besides, the consumption data can be transferred in different granularity for the selected household and various degrees of aggregation. Highly granular energy profiles of a single household need more measures for data protection than profiles of high granularity but aggregated over several households.

Some principles for ensuring data privacy are developed, i.e. transparency, legitimate purpose and proportionality. Within the context of household energy consumption profiles of high granularity and low aggregation a guideline is to keep these profiles should within the household.

Some basic approaches are given by Metke and Ekl [19] and Raabe [26]. Protocols for fraud and leakage detection as well as further statistical processing of meter measurements, without revealing individual meter readings are given by Kursawe, Kohlweiss and Danezis [17].

Household energy consumption profiles of high granularity make it is possible to detect active electrical devices and thus information about the lifesytle as shown by Müller [21] and critically discussed by Fox and Müller [7].

\section{SYSTEM ARCHITECTURE AND COMMUNICATION}

The main components of the system presented within this paper are: a smart meter, a smart energy controller (data storage) and mobile devices (smartphones). The system presented within this paper is based on the work of Kunold et al. [14]. Data of energy usage are continuously collected by a smart meter and transferred to a smart energy controller (SEC). The SEC serves as a storage device of energy consumption profiles within the household. Typically it can be represented by a WLAN router, for example a Fritz Box [9]. The Fritz Box offers the option to run additional applications, i.e. a data base system for storing energy profiles of high granularity [14]. From the SEC the profiles may be transferred wirelessly to a smartphone of the energy customer.

Data transfer between smart meter and SEC database can be achieved either by wire or wirelessly, e.g. WiFi or ZigBee [14].

The data storage within the SEC is represented by a SQL database, which holds information about energy usage and available tariffs.

Data access by smartphones is achieved by a set of Web Services, thus ensuring the system requirement of platform independency. 
The systems functionality is described by two scenarios. Each of the two scenarios represents a specific software and hardware environment. In the first scenario the actual data from a smart meter are stored in local database on a SEC [15]. This scenario provides access to current data of energy usage with high granularity and low aggregation (one household), but cannot provide long term data storage [25].

Within the second scenario packed information with high granularity and medium aggregation from the local data base within the SEC is transferred to the global data storage at the energy provider [25].The global database holds either long term data of low granulatity of one household or long term data of high granularity aggregated over several households.

\section{SYSTEM ARCHITECTURE FOR AN INHOUSE SCENARIO}

Information (energy profiles) are transmitted wirelessly (Wifi, ZigBee) or by wire to a data storage (database). The database is embedded in a smart energy controller (SEC), which is spatially located close to the smart meter. Additionally, within the SEC an embedded web server is implemented. The SEC has a limited performance and operational memory due to the requirement of a low energy usage. The location of the database within the SEC causes limitations concerning the database implementation regarding volume and performance.

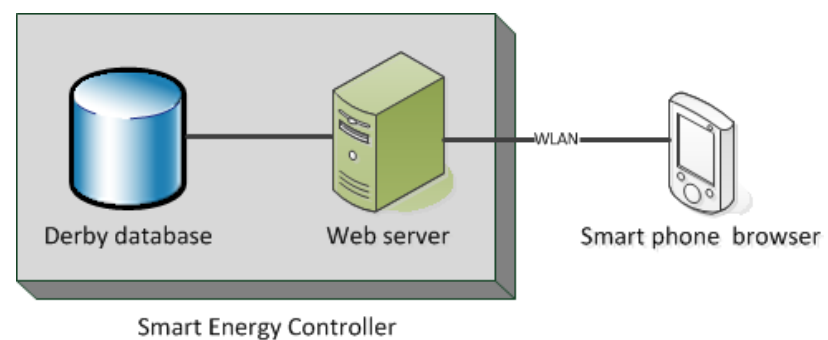

Fig. 1. - System and communication architecture of an inhouse scenario

Figure 1 shows the system's architecture. Limited hardware resources and other restrictive software requirements lead to Java as development software for the embedded system. A Jetty server is used as Java Servlet implementation for web services [5]. Moreover, Jetty provides a database access engine. Both features enable Jetty to be used as web server implementation. An Apache Derby database is installed as data storage [1]. Apache Derby is an open source relational database implemented entirely in Java. The particular advantage of Apache Derby is its small required disc space of about 2.6 MB.
The following diagram (Fig. 2) shows the system architecture and components.

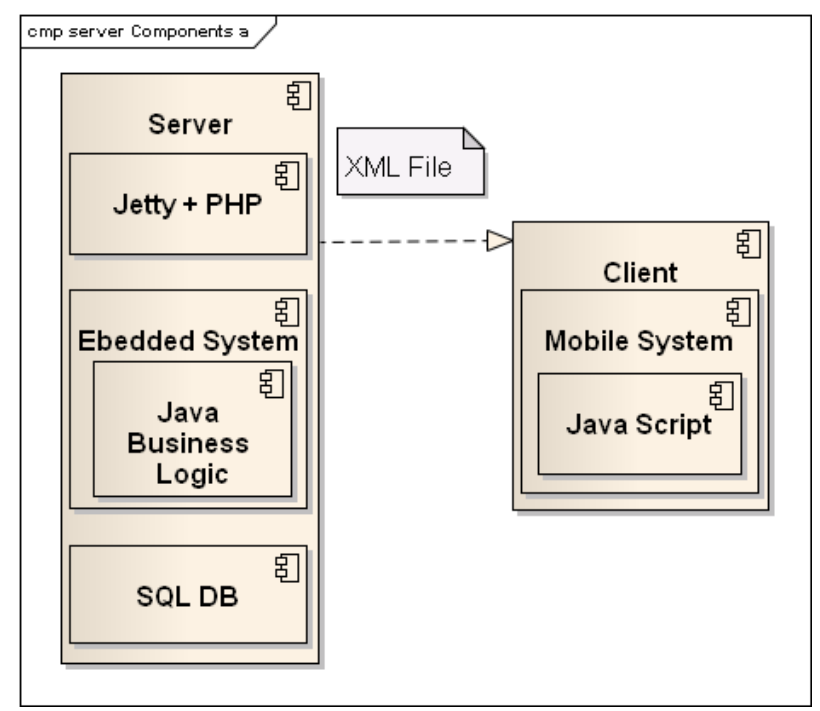

Fig. 2. - System and component diagramm for an inhouse scenario

\section{SYSTEM ARCHITECTURE FOR AN INHOUSE/PROVIDER SCENARIO}

The inhouse/provider scenario requires two server types. The first type is the server located on the embedded system, which holds high resolution and short life data. The second type is a global server, located at the energy provider. Local data are collected, compressed and stored into the global database. The global data storage is a PostgreSQL database. PostgreSQL is a fast object-relational database management system [23]. Data compression means at least reduction of the time resolution, for example: from one item per second sampling to one item per hour sampling. Fig 3 shows a system overview of the inhouse/provider scenario.

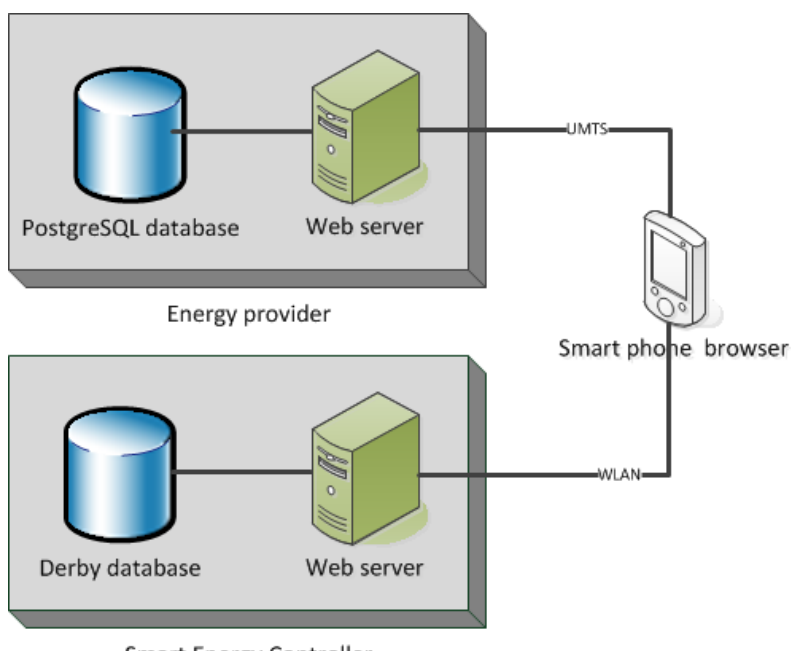

Fig. 3. - System Overview for an inhouse/provider scenario 
For flexible access to the provider's database web services located on the provider's server are used. It is possible to run the database and web services on different servers as well. The web services are using the Simple Object Access Protocol (SOAP). This enables other systems, like web server, mobile apps or other applications, to access data independently of database and mobile device platform.

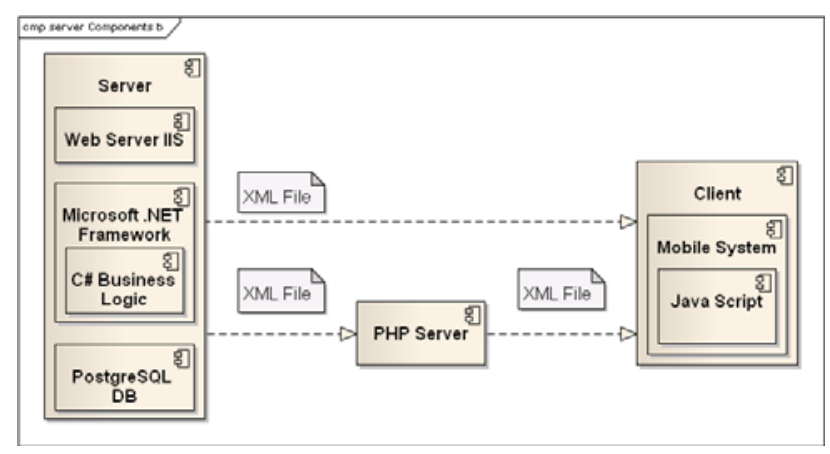

Fig. 4. - Component diagram for an inhouse/provider scenario

\section{DATA VISUALIZATION ON SMART PHONES}

The mobile device for visualization has to deliver information in a clear, intuitive and easy interpretable format. Nowadays there are numerous mobile devices available for customers [8], [10]. All those devices are based on different platforms and operating systems. That means that the presented system has to be platform independent. Moreover, mobile device have limited hardware resources: small display size, low performance in comparison to desktop computers. The system ergonomic design must take such limitation into account.

In this context the usability and compactness of the displayed information has a significant roll. The information priority is case and tariff sensitive. For different use cases the set of displayed information is varying.

For visualizing data on a mobile device there are two general approaches. The first option is a specially developed application. This application can be installed on a target device - smart phone, e.g. Apple iPhone. The second option is given by a web server, generating a web site which can be called by a browser from a mobile device.

The approach via an application represents a proprietary solution. Then the application adapts to the platform and can make use of all capabilities of the platform. This means an optimization in speed, functionality and design. The disadvantage is the missing flexibility, because the application is dedicated to the platform. In this case a specific application has to be developed.

The main advantage of the website approach is the platform independence. The web server may be called by a browser regardless of the used platform. The disadvantages are the difference in visualization between the platforms, no offline availability and the missing possibility to use the capabilities of the platform. Applications have direct access to the system resources like camera, Global Positioning System (GPS) and other peripheral devices. Some of these systems resources can be used by a website and websites can be stored, too. Therefore it is necessary that the device supports Hypertext Markup Language in Version 5 (HTML5) [27].

The selected option is the website approach. To minimize the disadvantages of the website approach, a framework is used. The jQuery mobile framework is based on the jQuery framework [12], a JavaScript Library. The jQuery mobile framework represents a user interface framework for website approaches independent of mobile device and platform. With this framework, it is easy to give the website approach a flexible app look-alike. With the app look-alike, the user has not to adjust himself from the accustomed use of the platform and the apps on this platform. The capabilities of the platform were unutilized. When the smart phone has access to the data, there is an access to the web server, too. Even the app needs access to the data and couldn't work without. So the missing offline availability of the web site is not a disadvantage in this use case. There are no complex graphical visualizations, which require the whole performance of the smart phone.

\section{VISUALIZATION of TARIFF DATA AND ENERGY USAGE}

Pueschel et al. [24] analyzed a household customer base of a local energy provider. They performed a segmentation of the household customer base concerning the motivation of household customers to use smartphones and change their habit of energy consumption. They identified several different segments of household customer base. To each of these segments a specific tariff may be associated. Further on, each tariff needs specific information for optimal use which has to be displayed on the smart phone. Consequently, specific information presentation formats for different tariffs have to be developed. These information presentation formats vary depending on the selected tariff.

The acceptance of smart metering systems needs a visualization of data on a smartphone in an intuitive and comprehensible way. Otherwise it would be too complicated for the user to comprehend the data and take decisions.

First, a load-dependent tariff was considered. In this scenario the household customer has an 
opportunity to watch his actual energy usage in real time mode and also, according to the selected tariff, receive notification messages or graphical presentation about energy usage in relation to tariff threshold. In this case the household customer can make a decision to adjust his usage behavior based on the price ruling. He can reschedule his energy intensive tasks to another time. For this kind of tariff the necessary information for the household customer is the current load.

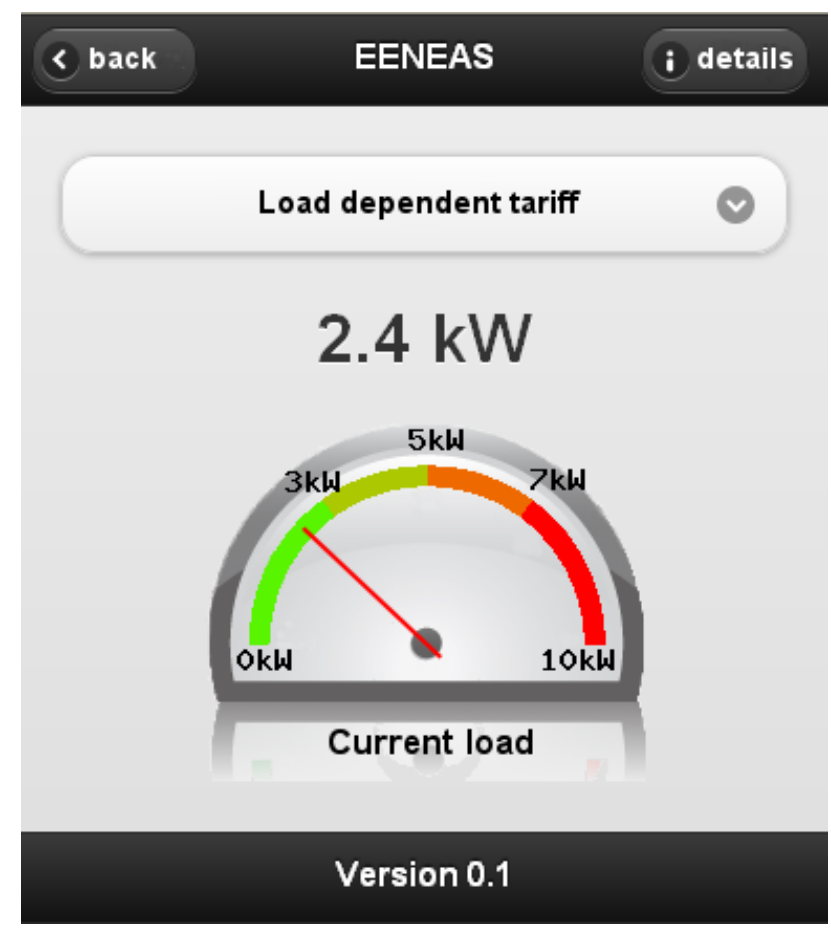

Fig. 5. - Visualizing current energy load for a load dependent tariff on a smartphone

A suitable visualization of the current load changing in time is achieved by a speedometer. The load is represented by the speedometer needle. The minimum of the speedometer is given by the base load, the maximum by the maximum load. The different tiers of a load dependent tariff are assigned by different colours. The size of classification is flexible and depends on the actual tariff (see 0).

Through the assistance of JavaScript the current load and hence the speedometer needle can be refreshed every five seconds without an interaction by the user. An advantage of the speedometer presentation is it's easiness to read.

Secondly, the visualization of a tariff depending on total energy usage is considered. This suits the requirements of data visualization within the inhouse/provider scenario. The household customer is enabled to watch his long term energy usage behavior.

The visualization of a tariff depending on total usage can be implemented by a scale like a thermometer (see Figure 6).

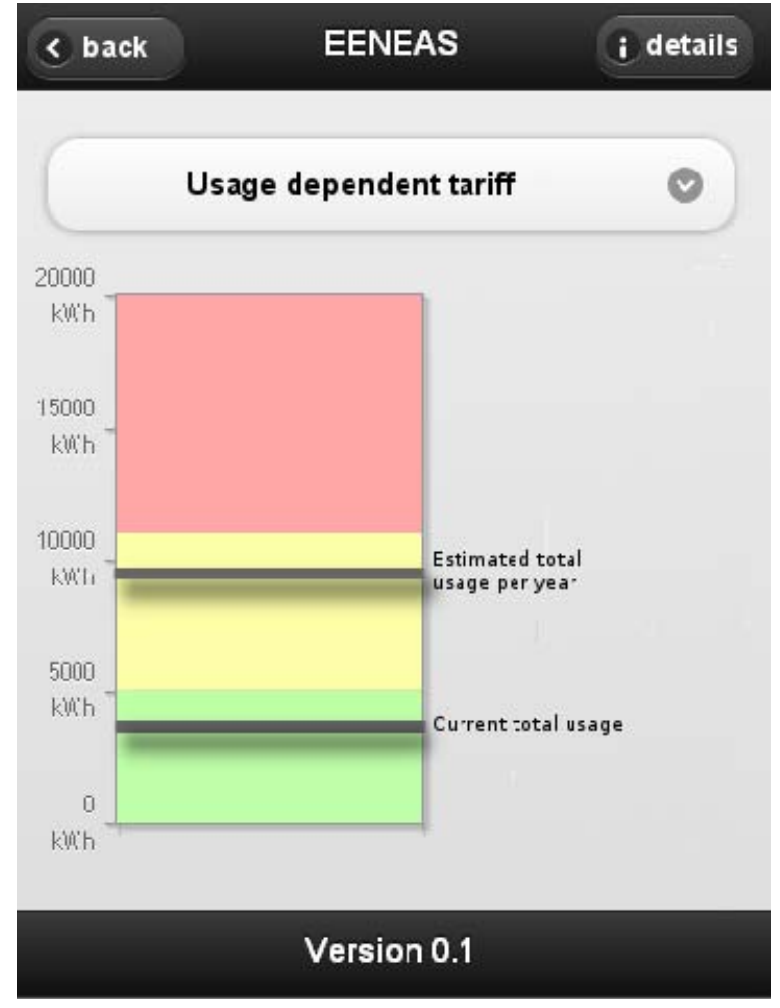

Fig. 6. - Visualizing a tariff depending on total usage of energy

Three different price categories are represented by different colours. The price of the energy unit increases, if the total energy usage exceeds certain threshold values. The current total usage of energy is presented together with an estimation of the total energy usage per year. The user is enabled to adapt his energy usage and prevent exceeding thresholds.

The estimation of total energy usage per is based on historical information of energy usage of the customer or comparable households.

Thirdly, a time dependent tariff is considered (see Figure 7). The visualization is implemented by using a time dependent graph of energy costs. The horizontal axis shows the time period of the last 24 hours to now. The vertical axis shows the costs of energy. The background of the graph presents periods of different energy prices (Euro/kWh) visualized by different colours.

This kind of tariff is essential for motivating household customers to react on demand response signals, i.e. price changes. For optimizing costs with a time-dependent tariff it is important to see the actual costs in comparison to those in other time slots.

For the load dependent tariff it is necessary that the data presented are up to date and presented close to real time, i.e. they are transferred from the SEC on to the smartphone. Otherwise variances in the usage are shown too late and it is not possible for the user to react. 


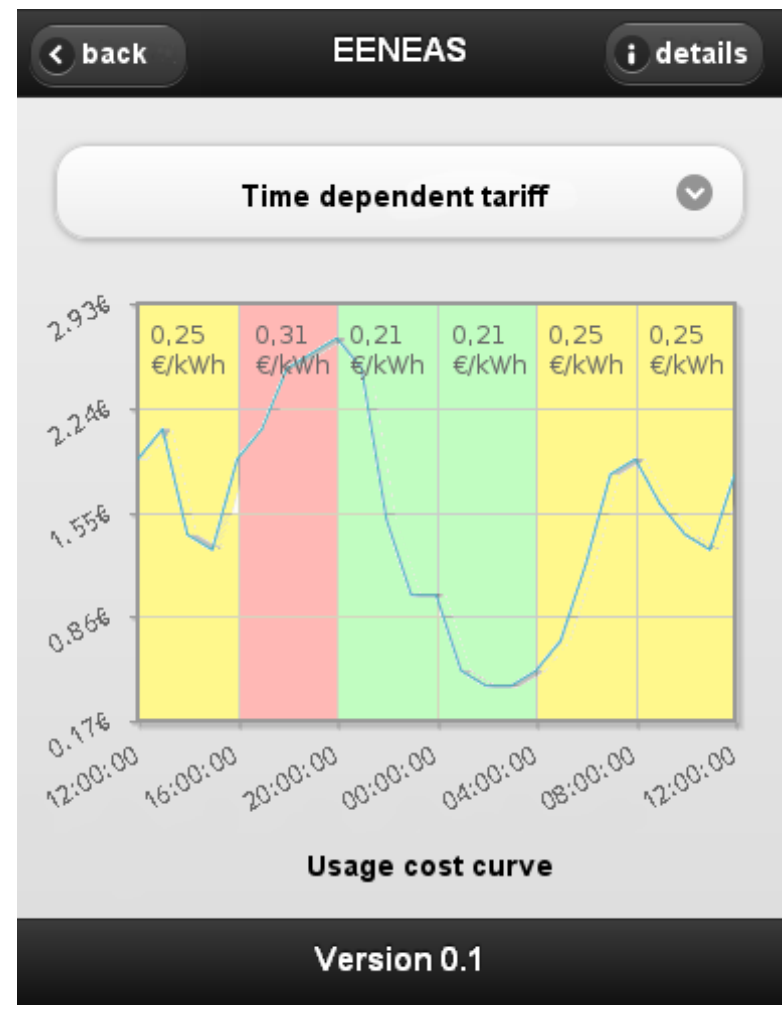

Fig. 7. - Visualizing a time dependent tariff

For the time dependent tariff as well current data are needed. Then current costs can be displayed. Again, this is necessary for the consumer to react.

The tariff depending on total energy usage does not need current data. The current amount of totally used energy may be transferred from the energy provider's database to the customer's smartphone. The expected customer reaction is not a short term reaction, but optionally a long term change in his general habit of energy usage.

Moreover, for assisting the household customer in monitoring his energy usage and for decision support a recommendation tool based on an interactive dialog is developed. The household customer can define certain devices by specific parameters, i.e. mean energy usage. Depending on the actual tariff and user defined parameters the recommendation tool generates optimal strategy for using each device (see Figure 8). In case of load dependent tariff, the system's recommendation avoids excess of the defined maximum load.

In case of time dependent tariff a time period is recommended for the device to use. The user has the opportunity to select the valid time period.

Moreover the user can select any available device to see how the load of the device acts on the total energy load profile. The result is classified in three stages: optimal, satisfied, bad. The corresponding colors are "green", "yellow" and "red".

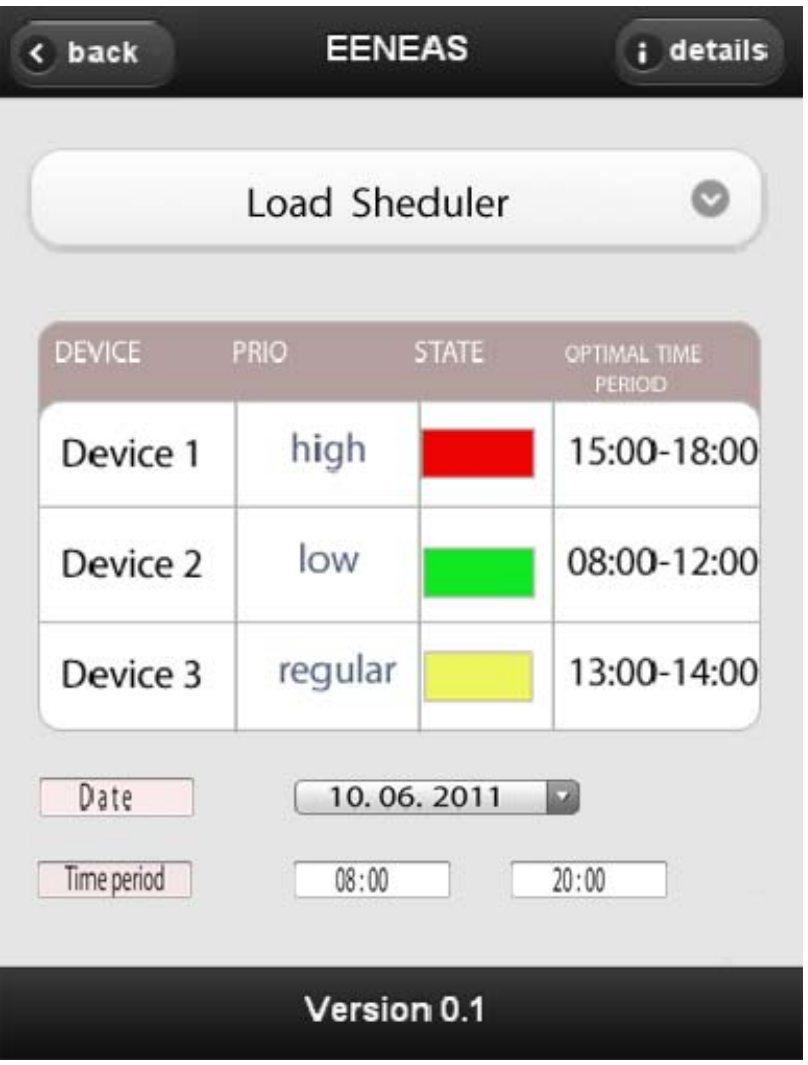

Fig. 8 - Load Sheduler

\section{RESUME}

The paper presents several approaches for visualizing energy and corresponding cost and tariff data on mobile devices like smart phones. The data are recorded by a smart meter and presented to a household customer to give him relevant information concerning his energy usage. Thus, the household customer is ubiquitously enabled to take decisions concerning the reduction of his energy usage or the shift of his energy load. Suitable and specific visualizations for different tariffs are presented.

The architecture of the system takes into account data privacy demands by using two different scenarios, an inhouse and a inhouse/provider scenario. The guideline for respecting data privacy concerns is keeping detailed profiles of the customer's energy usage within his household.

\section{ACKNOWLEDGEMENT}

This paper presents results developed by the FHEXTRA-project EENEAS funded by the federal state government of North-Rhine-Westfalia (Germany), DEW21 (Dortmund/Germany) and Lackmann group (Muenster/Germany). 


\section{REFERENCES}

[1] Apache DB Project, Apache Derby, http://db.apache.org/derby/. 30.06.2011.

[2] BMWi, E-energy project, http://www.eenergy.de/en/index.php, 2011, 30.6.2011.

[3] S. Borenstein, M. Jaske, A. Rosenfeld, Dynamic Pricing, Advanced Metering and Demand Response in Electricity Markets, Hewlett Foundation Energy Series, 2002.

[4] Dr. Neuhaus Telekommunikation GmbH, Data Visualization in Smart Metering Pilot Projects, http://www.neuhaus.de/English/Support/ZDUE /SMARTY\%20mCenter/Datasheets/DS SMA RTY mCenter 1v1.pdf, 29.06.2011.

[5] Eclipse Foundation, Jetty, http://www.eclipse. org/jetty/, 30.06.2011.

[6] Enexoma AG, Start into a Smart World, http://www.enexoma.de/index.php?id=163, 30.06.2011.

[7] D. Fox, K. J. Müller, Smart Grid-Legenden, in Gestaltungslinien für Sicherheit und Datenschutz im Energieinformationsgesetz, 2011.

[8] M. Franz, Im Gespräch mit Nokia: 'Bis zu zehn neue Symbian-Smartphones', http://www. netzwelt.de/news/87274-gespraech-nokia-zehnneue-symbian-smartphones.html, 2011, 29.06.2011.

[9] Fritz Box, http://www.avm.de/de/Produkte/ FRITZBox/index.php

[10] Gartner, Worldwide Smartphone Sales to End Users by Operating System in 2010, http://www.gartner.com/it/page.jsp?id=154301 4, 2011, 30.06.2011

[11] F. Gather, App oder Mobile Website? Nutzen!, in: mobile zeitgeistSPECIAL Das eMag zum Mobile Business Apps vs. Mobile Browser - Ist das Wettrennen entschieden? Ausgabe 1/11, 2011.

[12] jQuery Project, www.jquery.com, 30.6.2011.

[13] M. Keck, App-Usability - Herausforderungen und Guidelines, http://www.eresult.de/ studien_artikel/forschungsbeitraege/app-usabili ty.html, (30.6.2011)

[14] I. Kunold, M. Kuller, Modell für einen e-energy Controller zur dynamischen Steuerung des Energieverbrauchs von Einfamilienhäusern und KMU, in: Smart Energy 2010: Innovative, IKT-orientierte Konzepte für den Energiesektor der Zukunft (Großmann, U., Kunold, I.(Hrsg.)), vwh-Verlag, 2010.

[15] I. Kunold, M. Kuller, N. Karaogla, A system concept of an energy information system in flats using wireless technologies and smart metering devices, in the 6th IEEE International Conference on Intelligent Data Acquisition and Advanced Computing Systems IDAACS'2001
(September 15-17, 2011) Prague, Czech Republicю

[16] J. Kohlbrecher, S. Hakobyan, J. Pickert, U. Grossmann, Visualizing energy information on mobile devices, in the 6th IEEE International Conference on Intelligent Data Acquisition and Advanced Computing Systems IDAACS'2001 (September 15-17, 2011) Prague, Czech Republic.

[17] K. Kursawe, M. Kohlweiss, G. Danezis, Privacy-friendly aggregation for the smart-grid, in Privacy Enhancing Technologies - 11th International Symposium, 2011, p. 175-191.

[18] R. Leung, J. McGrenere, P. Graf, Age-related differences in the initial usability of mobile device icons, Behaviour \& Information Technology, 2009, pp. 1-14.

[19] A. R. Metke, R. L. Ekl, Security technology for smart grid networks, in IEEE Transaction on Smart GRID, (1) 1 (2010).

[20] Microsoft Corporation, Internet Information Services (IIS) 7.5, http://www.microsoft.com/ windowsserver2008/en/us/internet-informationservices.aspx, 30.6.2011.

[21] K. J. Müller, Gewinnung von verhaltensprofilen am intelligenten stromzähler, in Datenschutz und Datensicherheit - DuD, (34) 6 (2010).

[22] J. Nielsen, Mobile Usability, http://www.useit. com/alertbox/mobile-usability.html, 2009, 30.6.2011.

[23] PostgreSQL Global Development Group, PostgreSQL, http://www.postgresql.org/, 30.06.2011.

[24] S. Püschel, U. Großmann, Segmentierung des kundenstamms eines energieversorgerszur einführung von smart metering systemen ergebnisse einer kundenbefragung, in Smart Energy 2010: Innovative, IKT-orientierte Konzepte für den Energiesektor der Zukunft (Großmann, U., Kunold, I.(Hrsg.)), vwhVerlag, 2010.

[25] S. Püschel, U. Großmann, Datenschutzaspekte bei der Einführumg intelligenter Energiezähler aus Sicht der Marktteilnehmer, in Smart Energy 2011: Innovative, IKT-orientierte Konzepte für den Energiesektor der Zukunft (Großmann, U., Kunold, I.(Hrsg.)), vwh-Verlag, 2011.

[26] O. Raabe, Datenschutz im SmartGrid, in Datenschutz und Datensicherheit - DuD, (34) 6 (2010).

[27] W3C, HTML5 A vocabulary and associated APIs for HTML and XHTML, http://www.w3.org/TR/html5/, 2011, 29.06.2011.

[28] W3C, MobileOK Checker, http://validator. w3.org/mobile/, 30.6.2011. 


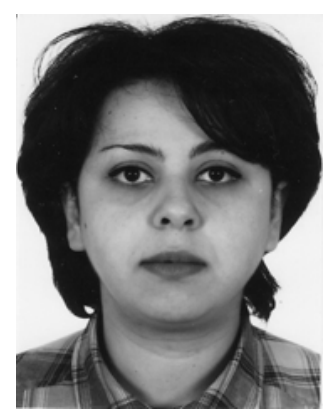

Syuzanna Hakobyan, M.Sc.,

Studies of Information

Technology and Computer

Systems at Armenian State

Engineering University,

Eriwan. Current position:

Research associate at

Business Department of

University of Applied Sciences

and Arts, Dortmund; member of MBMS research group; $P h D$

student at University Duisburg-Essen, research focus: localization algorithms in WLAN systems / EEnergy.

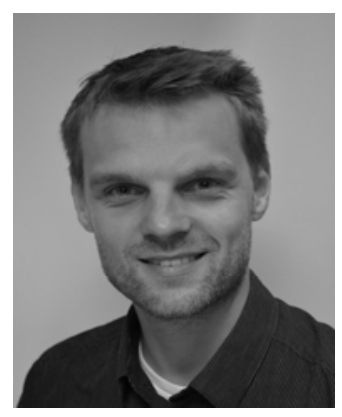

Jan-Philipp Kohlbrecher, M.Sc., Studies of Medical Informatics at University of Applied Sciences and Arts Dortmund, current position: Research associate at Business Department of University of Applied Sciences and Arts, Dortmund; member of MBMS research group. research focus: localization algorithms in WLAN systems / E-Energy

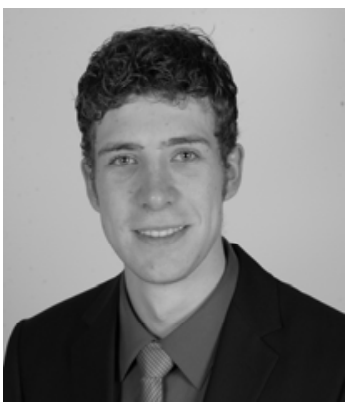

Johannes Pickert, cand. inf., Studies of Information Technology at University of Applied Science and Arts, Dortmund. current position: member of MBMS research group, research focus: developement of mobile applications esp. for 'Smart Metering'

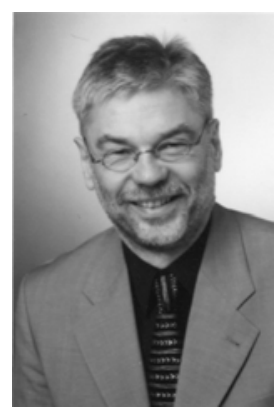

Prof. Dr. Uwe Grossmann, Studies of mathematics and information technology (Bochum University, Germany), PhD in mathematics (Bochum University, Germany), research associate at Essen University and Max-Planck-Institute Dortmund, project manager computer aided manufacturing at mbp software \& systems gmbh., Current position: professor of mathematics and business information technology at University of Applied Sciences and Arts Dortmund; speaker of research group 'mobile business - mobile systems', research focus: mobile business, wireless mobile systems, location based sercices, WiFi, RFID/NFC 